\title{
Benzene toxicokinetics in humans: exposure of bone marrow to metabolites
}

Karen H Watanabe, Frédéric Y Bois, Joan M Daisey, David M Auslander, Robert C Spear

\begin{abstract}
A three compartment physiologically based toxicokinetic model was fitted to human data on benzene disposition. Two separate groups of model parameter derivations were obtained, depending on which data sets were being fitted. The model was then used to simulate five environmental or occupational exposures. Predicted values of the total bone marrow exposure to benzene and cumulative quantity of metabolites produced by the bone marrow were generated for each scenario. The relation between cumulative quantity of metabolites produced by the bone marrow and continuous benzene exposure was also investigated in detail for simulated inhalation exposure concentrations ranging from 0.0039 $\mathrm{ppm}$ to $150 \mathrm{ppm}$. At the level of environmental exposures, no dose rate effect was found for either model. The occupational exposures led to only slight dose rate effects. A 32 ppm exposure for 15 minutes predicted consistently higher values than a 1 ppm exposure for eight hours for the total exposure of bone marrow to benzene and the cumulative quantity of metabolites produced by the bone marrow. The general relation between the cumulative quantity of metabolites produced by the bone marrow and the inhalation concentration of benzene is not linear. An inflection point exists in some cases leading to a slightly $S$ shaped curve. At environmental levels (0.0039-10 ppm) the curve bends upward, and it saturates at high experimental exposures (greater than 100 ppm).
\end{abstract}

(Occup Environ Med 1994;51:414-420)

Mechanical

University of

California, Berkeley

K H Watanabe

D M Auslander

Lawrence Berkeley Laboratory F Y Bois

J M Daisey

School of Public

Health, University of California, Berkeley R C Spear

Requests for reprints to: Dr Frédéric Y Bois, Indoor Environment Program, mail stop 90-3058, Lawrence Berkeley Laboratory, Berkeley, Accepted for publication 4 February 1994

in the human environment. Workers petroleum, petrochemical, and other related industries are exposed through inhalation of benzene concentrations of the order of one part per million (ppm).$^{1-5}$ The general population is widely exposed to benzene in the atmosphere due to the volatile nature of petroleum, exhaust pipe emissions from motor vehicles, and emissions from other combustion sources. These exposures are typically in parts per billion (ppb).$^{67}$ Both workers and the general population are also exposed to benzene from cigarettes, either directly through smoking or indirectly from tobacco smoke in the environment. Within both populations, exposures can be nearly continuous or can involve intermittent peaks against some background level.

Estimates of the risks of benzene exposures in the general population are based on relatively simple extrapolations from high level exposures. Relations between exposure and tissue dose (and risk) can be non-linear, however, if saturable metabolic processes are involved. In such a case, to use the external exposure to the parent compound is incorrect. Physiologically based toxicokinetic models can provide more accurate estimates of risks by predicting tissue exposure to the active compound(s).

Many of the published experimental studies describe attempts to fit linear or compartmental toxicokinetic models to benzene toxicokinetic data. Recently, Travis et al developed a physiologically based toxicokinetic model for benzene in humans. ${ }^{8}$ No formal model parameter derivation was performed by Travis et al. ${ }^{8}$ Reference values were used for most of the model parameters. The metabolic parameters were then adjusted to visually fit the data. By contrast, in the work reported here, an attempt is made to formally fit a physiologically based toxicokinetic model. Multiple parameter sets were obtained that fit the data. These parameter sets were then used to investigate the toxicokinetics of benzene for realistic (environmental and occupational) exposures, focusing particularly on dose rate effects. One benefit of a physiological model is that it is reasonable to expect that extrapolations of such a model have more basis in reality than a purely empirical model. If the quantity of metabolites produced in the bone marrow is the relevant measure on which leukaemia risk estimates should be based, it is useful to have the relation between such a quantity and the exposure concentration. Thus target site exposures, difficult to measure experimentally, were also determined by simulation for a wide range of inhalation concentrations.

\section{Methods}

EXPERIMENTAL DATA

Data from four inhalation exposure studies were used to fit the model. Teisinger and Fiserova-Bergerova, ${ }^{9}$ as reported by Docter and Zielhuis, ${ }^{10}$ measured urinary phenol and its conjugates during and after exposure to 25 ppm of benzene for eight hours. The results 
are for a single subject, but this is not clearly indicated.

Srbova et al made measurements in 23 subjects, but reported the expired air and venous blood concentrations in only one person during a 90 minute exposure and up to 6.5 hours after exposure. ${ }^{11}$ The average benzene exposure concentration was about $98 \mathrm{ppm}$. The exact exposure concentrations reported at 15 minute intervals were used in the simulations, however.

Data reported by Sato et al for the average end tidal air and venous blood concentrations for three men were also used. ${ }^{12}$ The benzene exposure concentration was $25 \mathrm{ppm}$ for a duration of two hours. The measurements after exposure were made for up to five hours. A second paper by Sato et al reported the mean and SD of benzene in end tidal air and venous blood concentrations after exposure to 25 ppm for two hours. ${ }^{13}$ The results were reported for five men and five women separately. The end tidal air measurements were made up to five hours after the exposure. Venous blood measurements were made both during and after exposure.

We code these studies as $T$ for Teisinger and Fiserova-Bergerova, ${ }^{9} \mathrm{Sr}$ for Srbova et al, ${ }^{11}$ Sa74 for Sato et al, ${ }^{12}$ and Sa75 for Sato et al. ${ }^{13}$ The results of Sato $e t a l^{13}$ are treated as two separate experiments (men and women) for a total of five experiments used in the model parameter derivation.

\section{MODEL STRUCTURE AND PARAMETER DERIVATION}

A physiologically based toxicokinetic model, previously validated, ${ }^{14}$ was fitted to benzene concentrations in expired air and venous blood, and urinary phenol data. The model includes three compartments: central, bone marrow, and fat tissue compartment. Inhalation or ingestion exposures can be simu- lated. Benzene is eliminated by exhalation or through saturable (Michaelis-Menten) metabolism in the central and bone marrow compartments. The model requires the definition of 16 physiological variables calculated from their associated scaling coefficients. Table 1 gives the sampling ranges of the scaling coefficients, hereafter referred to as parameters. For fitting, the Monte Carlo technique of Spear et $a l^{14-16}$ was used. In a given Monte Carlo simulation, the parameters were selected randomly from uniform or $\log$ uniform distributions. The system of equations describing the model was solved numerically to make predictions for each criterion and the quality of the fit was assessed. The fit was declared acceptable if all predicted values (concentrations or metabolite amounts) were within $50 \%$ of the corresponding value of published data. Three to four experimental data points were chosen to summarise the time course of measurements made during exposure and after exposure. A table of the criteria is available on request. The parameter sets yielding good fits (meeting these criteria) were saved and labelled PASS parameter sets.

To improve sampling efficiency (finding PASSs), 3000 preliminary simulations were performed. From these 3000 runs, PASS parameter sets providing good fits to the data for each of the five experiments, considered individually, were extracted. The bounds of the parameter ranges (the lowest and the highest PASS parameter values) were determined. The intersection of the PASS parameter ranges for the five experiments was used for the parameter sampling in the subsequent Monte Carlo runs. Simulations were performed until 20 PASS parameter sets were found.

A cluster analysis was performed on the final PASS parameter sets obtained through Monte Carlo simulations to verify whether or

Table 1 Physiological variables and their scaling coefficients (SCs) for benzene toxicokinetics in humans, with the corresponding initial Monte Carlo sampling ranges ${ }^{\dagger}$

\begin{tabular}{|c|c|c|c|c|}
\hline Physiological variable & $S C s$ & Multiplier & SC lower limit & SC upper limit \\
\hline $\begin{array}{l}\text { Cardiac output } \\
\text { Alveolar ventilation } \\
\text { Blood flows: }\end{array}$ & $\begin{array}{l}\text { Sc-Flow-tot } \\
\text { VPerf-rat }\end{array}$ & $\begin{array}{l}\text { BW }^{0.75} \\
\text { Cardiac output }\end{array}$ & $\begin{array}{l}0 \cdot 188 \\
0 \cdot 500\end{array}$ & $\begin{array}{l}0 \cdot 543 \\
1 \cdot 50\end{array}$ \\
\hline $\begin{array}{l}\text { Bone marrow } \\
\text { Fat } \\
\text { Central compartment }\end{array}$ & $\begin{array}{l}\text { Flow-bm } \\
\text { Flow-fat } \\
\text { Flow-cen }\end{array}$ & $\begin{array}{l}\text { Cardiac output } \\
\text { Cardiac output } \\
\text { Cardiac output }\end{array}$ & $\begin{array}{l}0.00821 \\
0.0203 \\
\ddagger\end{array}$ & $\begin{array}{l}0.0665 \\
0.0784 \\
\ddagger\end{array}$ \\
\hline Volumes: & & & & \\
\hline Bone marrow & V-bm & BW & $0 \cdot 010$ & 0.060 \\
\hline $\begin{array}{l}\text { Fat } \\
\text { Central compartment }\end{array}$ & $\begin{array}{l}\text { V-fat } \\
\text { V-cen }\end{array}$ & BW & $0 \cdot 109$ & 0.337 \\
\hline $\begin{array}{l}\text { Central compartment } \\
\text { Blood/air partition coefficient }\end{array}$ & $\begin{array}{l}\text { V-cen } \\
\text { PCb-art }\end{array}$ & BW & $\$_{1.66}$ & $\$ 17.9$ \\
\hline Tissue/blood partition coefficients: & & & 100 & 17.9 \\
\hline $\begin{array}{l}\text { Bone marrow } \\
\text { Fat } \\
\text { Central compartment }\end{array}$ & $\begin{array}{l}\text { PCb-bm } \\
\text { PCb-fat } \\
\text { PCb-cen }\end{array}$ & $\begin{array}{l}1 \\
1 \\
1\end{array}$ & $\begin{array}{c}3 \cdot 03 \\
23 \cdot 0 \\
2 \cdot 02\end{array}$ & $\begin{array}{l}29 \cdot 3 \\
70 \cdot 5 \\
20 \cdot 1\end{array}$ \\
\hline Maximum rate of metabolism, Vmax: & & & & \\
\hline $\begin{array}{l}\text { Central compartment } \\
\text { Bone marrow }\end{array}$ & $\begin{array}{l}\text { Vab-cen } \\
\text { Vab-bm }\end{array}$ & $\begin{array}{l}\text { BW } \\
\text { Vab-cen }\end{array}$ & $\begin{array}{l}0.00104 \\
0.020\end{array}$ & $\begin{array}{l}0 \cdot 170 \\
0 \cdot 300\end{array}$ \\
\hline Vmax/Km ratios: & & & & \\
\hline $\begin{array}{l}\text { Central compartment } \\
\text { Bone marrow }\end{array}$ & $\begin{array}{l}\text { Kab-cen } \\
\text { Kab-bm }\end{array}$ & $\begin{array}{l}1 \\
1\end{array}$ & $\begin{array}{l}0.00533 \\
0.000358\end{array}$ & $\begin{array}{l}0.362 \\
0.495\end{array}$ \\
\hline Elimination rate constant & Km-out & 1 & 0.000211 & 0.0028 \\
\hline $\begin{array}{l}\text { Fraction of metabolites excreted as phenol } \\
\text { or phenol conjugates }\end{array}$ & Ph fraction & 1 & 0.600 & 1.00 \\
\hline
\end{tabular}


Table 2 Exposures tested for predictions of the quality of metabolite formed in the bone marrow and the bone marrow exposure to benzene."

\begin{tabular}{|c|c|c|c|c|}
\hline Exposures & $\begin{array}{l}\text { Continuous } \\
\text { background } \\
\text { concentration } \\
\text { (ppm)† }\end{array}$ & $\begin{array}{l}\text { Peak exposure } \\
\text { concentration } \\
(p p m) t\end{array}$ & $\begin{array}{l}\text { Peak exposure } \\
\text { length (min) }\end{array}$ & $\begin{array}{l}\text { TWA benzene } \\
\text { exposure } \\
\left(\mathrm{mg} / \mathrm{m}^{3}\right)\end{array}$ \\
\hline $\begin{array}{l}\text { Environmental: } \\
\text { I Environmental } \\
\text { background } \neq\end{array}$ & 0.0039 & - & - & 0.0125 \\
\hline II Petrol pumping & $\begin{array}{l}0.0036 \\
0.00062\end{array}$ & $\begin{array}{l}0.092 \\
0.084\end{array}$ & $\begin{array}{l}15 \\
20\end{array}$ & $\begin{array}{l}0.0125 \\
0.0132\end{array}$ \\
\hline $\begin{array}{l}\text { Occupational: } \\
\text { IV OSHA PEL } \\
\text { V }\end{array}$ & E & $\begin{array}{r}1 \cdot 0 \\
32 \cdot 0\end{array}$ & $\begin{array}{r}480 \\
15\end{array}$ & $\begin{array}{l}0.764 \\
0.764\end{array}$ \\
\hline
\end{tabular}

^Body weight of $70 \mathrm{~kg}$ was used for all simulations.

To convert to $\mathrm{mg} / \mathrm{l}$ multiply by 0.003207 , assuming $\mathrm{T}=25^{\circ} \mathrm{C}$ and $\mathrm{P}=1 \mathrm{~atm}$.

$\ddagger$ Indoor average urban exposure. ${ }^{\circ}$

Peak exposures at time 0 and every 5040 min thereafter. ${ }^{7}$

TTwo cigarettes smoked, at 0600 , noon, and 1800 every day during the week. ${ }^{\circ}$

Table 3 Parameter range results obtained from the Monte Carlo sampling*

\begin{tabular}{|c|c|c|c|c|}
\hline \multirow[b]{2}{*}{ Scaling coefficient } & \multicolumn{2}{|l|}{$T-S r t$} & \multicolumn{2}{|l|}{ Sa74-Sa75 } \\
\hline & Lower limit & Upper limit & Lower limit & Upper limit \\
\hline Sc-flow-tot & $0 \cdot 297$ & 0.477 & 0.38 & 0.52 \\
\hline VPerf-rat & 0.547 & 1.08 & 0.725 & $1 \cdot 17$ \\
\hline Flow-bm & 0.00969 & 0.0613 & 0.015 & 0.0612 \\
\hline Flow-fat & 0.0504 & 0.0759 & 0.0531 & 0.0757 \\
\hline V-bm & 0.0193 & 0.0592 & 0.0231 & 0.0587 \\
\hline V-fat & $0 \cdot 138$ & 0.313 & $0 \cdot 125$ & $0 \cdot 31$ \\
\hline PCb-art & 6.5 & 10.9 & 12 & $17 \cdot 1$ \\
\hline PCb-bm & $6 \cdot 31$ & $27 \cdot 1$ & $5 \cdot 14$ & $27 \cdot 3$ \\
\hline PCb-fat & $25 \cdot 4$ & 68 & $24 \cdot 2$ & 61.9 \\
\hline PCb-cen & $2 \cdot 02$ & $2 \cdot 62$ & 2.01 & 2.63 \\
\hline Vab-cen & 0.017 & 0.168 & 0.0316 & 0.167 \\
\hline Vab-bm & 0.0452 & 0.271 & 0.0528 & $0 \cdot 281$ \\
\hline Kab-cen & 0.00778 & 0.0169 & 0.0113 & 0.0209 \\
\hline Kab-bm $\S$ & 0.000475 & $0 \cdot 128$ & 0.000505 & 0.0804 \\
\hline Km-out & 0.0022 & 0.00268 & 0.000996 & 0.00263 \\
\hline $\mathrm{Ph}$ fraction & 0.607 & 0.786 & 0.624 & 0.956 \\
\hline
\end{tabular}

^Sampled uniformly except where otherwise noted.

TT-Sr: Teisinger and Fiserova-Bergerova ${ }^{9}$ and Srbova et al. ${ }^{11}$

$\$$ Sa74-Sa75: Sato et al. ${ }^{12} 13$

Sampled log uniformly. selected to represent a wide range of exposures, from the average population exposure to the occupational exposure at the current standards. For the general population, continuous and intermittent peak exposure scenarios that provided the same total inhalation dose were constructed (I and II, table 2). An air concentration of $0.0039 \mathrm{ppm}$ benzene was assumed for the continuous background exposure scenario. This concentration is roughly the 80 th percentile of the personal exposures measured for 50 people in Los Angeles in May, $1984 .^{6}$ These 50 people were randomly selected to represent a population of 330000 residents of the South Bay section of Los Angeles.

The second intermittent exposure scenario, the petrol pump scenario, assumes a continuous background exposure of $0.0036 \mathrm{ppm}$ benzene in air. This models a subject refuelling his or her vehicle with unleaded petrol at 0700 on Monday and 1900 on Thursday. The refuelling process lasts 15 minutes and the average concentration of benzene in air is $0.092 \mathrm{ppm}$. This concentration was the geometric mean of the benzene concentrations measured in short term personal air samples of service station attendants in three locations in the United States. ${ }^{7}$

The third scenario, encountered by some members of the general population, was based on benzene exposures of a light smoker (six cigarettes a day) representing a total inhalation target dose of $300 \mu \mathrm{g}$ a day. Main stream cigarette smoke provides a benzene dose of about $50 \mu \mathrm{g}$ per cigarette based on measurements of main stream emissions of $1 \mathrm{R} 4 \mathrm{~F}$ cigarettes, a reference cigarette. ${ }^{1819}$ This exposure scenario assumes a continuous background concentration of $0.00062 \mathrm{ppm}$ benzene in air, which is at about the 10th percentile of the personal exposures measured for Los Angeles residents in May, $1984 .{ }^{6}$ Against that background, the smoker was assumed to smoke six cigarettes a day, two at 0600, at noon, and at 1800,10 minutes exposure a cigarette, $50 \mu \mathrm{g}$ benzene a cigarette.

For the worker population, a continuous exposure of $1 \mathrm{ppm}$ over an eight hour work day and a peak exposure of $32 \mathrm{ppm}$ for 15 minutes a day were selected (IV and V table 2). These model exposures give the same total
Figure 1 Quality of fit. Model predicted $v$ observed (experimental) data values. The bounds of $50 \%$ are indicated by the thin lines. (A) Data from Teisinger and FiserovaBergerova ${ }^{9}$ and Srbova, $e$ al. ${ }^{\prime \prime}$ Twenty predictions were made for each of 10 observed values. (B) Data from Sato et al ${ }^{12}$ Twenty predictions were made for each of 26 observed values.
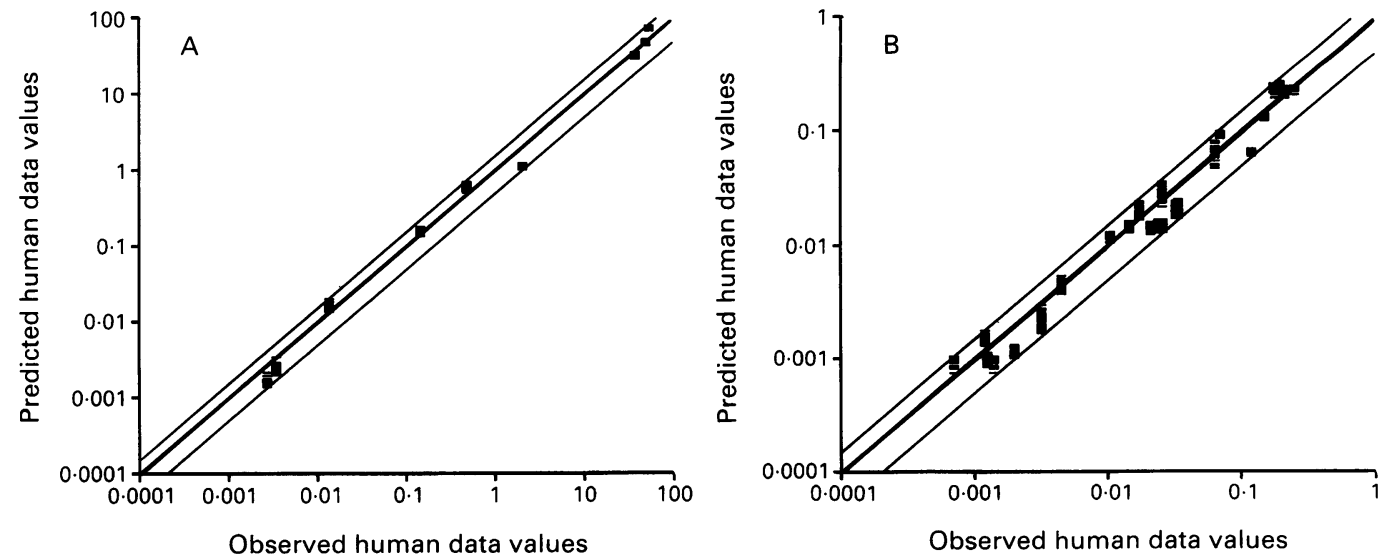
Figure 2 Quantity of metabolite formed in the bone marrow over one week at steady state for environmental exposures I-III and occupational exposure IV and $V$. (A) Model based on data from Teisinger and Fiserova-Bergerova ${ }^{9}$ and Srbova et al ${ }^{11}$ (B) Model based on data from Sato et al. ${ }^{12} 13$ Connected markers are the output from each PASS parameter set.

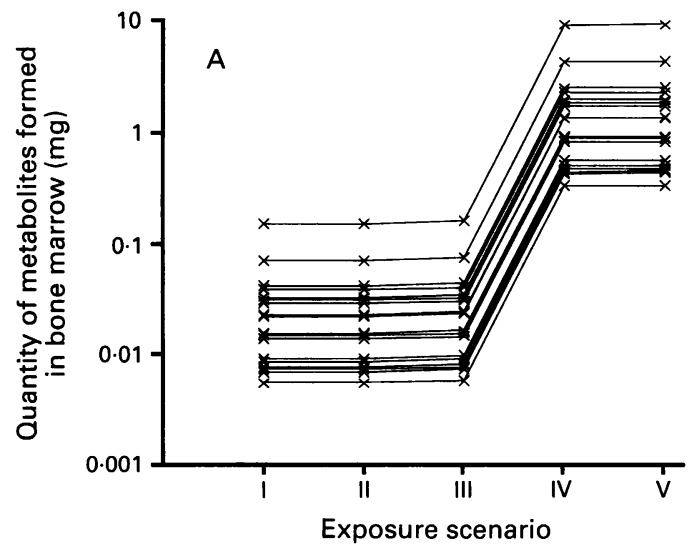

exposure $(480 \mathrm{ppm} \times \mathrm{min})$. The $1 \mathrm{ppm}$ exposure is the current Occupational Safety and Health Administration (OSHA) permissible exposure level (PEL). The $32 \mathrm{ppm}$ for 15 minutes exposure would be in violation of the OSHA short term exposure level (STEL) of 5 ppm for 15 minutes.

CUMULATIVE QUANTITY OF METABOLITES V INHALATION CONCENTRATION OF BENZENE After parameter derivations of data for exposures of 25 and $98 \mathrm{ppm}$ benzene, our model was used to make predictions of Qmet-bm at lower and higher exposure concentrations. These concentrations ranged from 0.0039 to $150 \mathrm{ppm}$ and were simulated as continuous exposures.

\section{Results}

DERIVATION OF PARAMETER SETS

Parameter sets producing simulation results that pass all the goodness of fit criteria were not found. Two groups of parameter sets were obtained: one that fits both $\mathrm{T}$ and $\mathrm{Sr}$ data; and another group that fits Sa74 and Sa75 data. When the T-Sr PASS parameter sets are used to simulate the Sa74-Sa75 data, four predicted values are always below the $50 \%$ criteria limits. Similarly, when the Sa74-Sa75 PASS parameter sets are used to simulate the $\mathrm{T}-\mathrm{Sr}$ data, three predicted values are always too high. The cluster analysis confirmed this result. Nearly 2.7 million simulations were needed to find 20 parameter sets fitting the $T$ -

Figure 3 Quantity of metabolite formed in bone marrow over one week at steady state $v$ the inhalation concentration. First five out of 20 curves obtained by fitting Sa74 and Sa75 data.

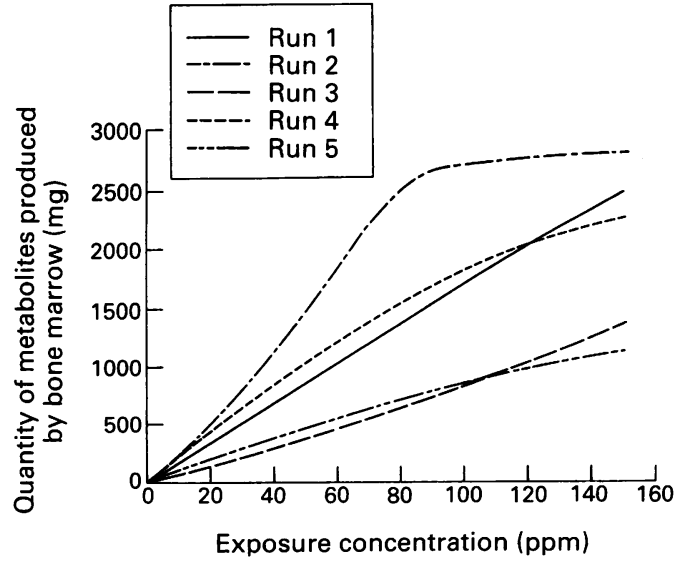

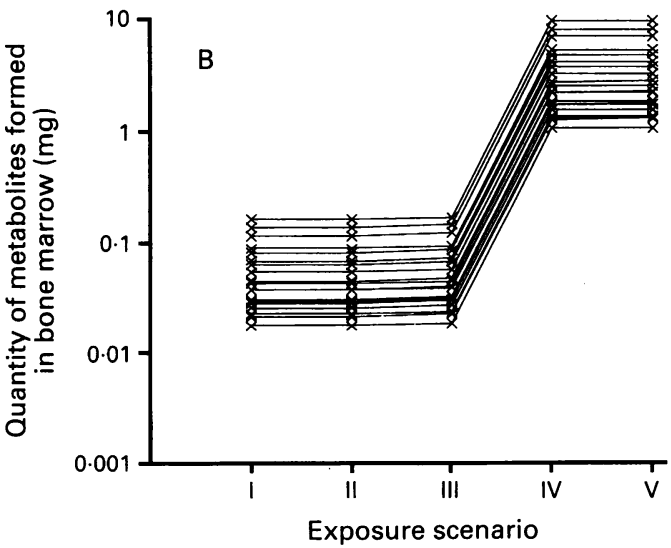

Sr data. Fitting Sa74 and Sa75 was easier. About 500000 runs were needed to obtain 20 parameter sets that fitted.

Figure 1(A) shows the 20 predicted $v$ observed values for all $\mathrm{T}-\mathrm{Sr}$ data, with the model fits to these data (the data represent different measurements expressed in different units). A perfect fit to the data would have all the points on the diagonal $(y=x)$. Figure 1(B) shows the 20 predictions for all Sa74 and Sa75 data, with the model fits to these data.

\section{EXPOSURE SIMULATIONS}

Figure 2 (A and B) plots Qmet-bm for exposure scenarios I-V. A set of connected markers represents the output from the model from one PASS parameter set. Exposure scenarios I and II have the same exposure time weighted average (TWA) and identical results predicted for Qmet-bm; thus no dose rate effects occur. The Qmet-bm for exposure V is consistently higher than the Qmet-bm values for exposure IV. The relative differences range from $0.13 \%$ to $4.6 \%$ (predictions from both $\mathrm{T}-\mathrm{Sr}$ and Sa74-Sa75 derivations). The predictions for areas under the curves followed similar trends. No difference was seen between the areas under the curves for exposures I and II. The relative differences for exposures IV and $\mathrm{V}$ ranged from $0.20 \%$ to $11 \%$ based on predictions from both parameter derivations, therefore showing slight exposure rate effects.

CUMULATIVE QUANTITY OF METABOLITES V INHALATION CONCENTRATION OF BENZENE Figure 3 is a plot of Qmet-bm $v$ exposure concentration generated by the first five parameter sets fitting Sa74-Sa75 data. Of the 20 parameter sets, 11 sets generate $S$ shaped curves such as runs 1 and 2 . Four curves look like run 3, which increases more than linearly with concentration. The rest look like curves 4 and 5 where no $S$ shape is seen and saturation is beginning. Of the 20 curves generated by $\mathrm{T}$-Sr parameter sets, eight curves look like runs 1 and 2, two curves look like run 3, and seven curves behave like runs 4 and 5 . In this group there were three parameter sets that generate seemingly straight lines over the range of concentrations studied. Figure 4 plots the slopes calculated between adjacent points $v$ the mean inhalation concentration between the two points. From this plot it is 
Figure 4 Slope between each pair of adjacent points in fig $3 v$ the mean concentration between these two points.

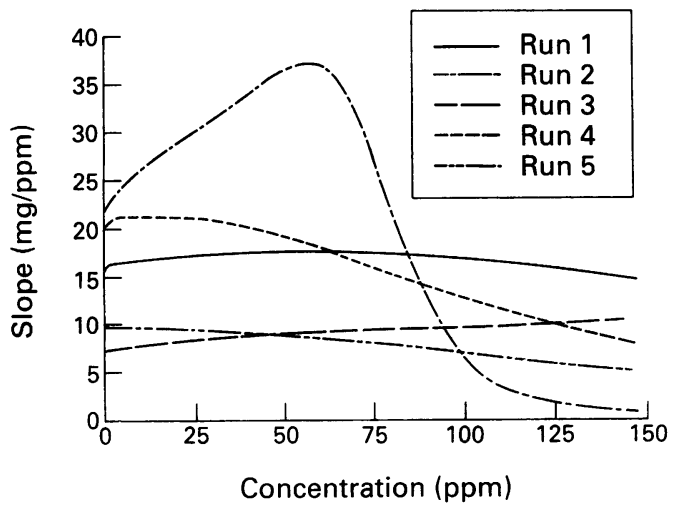

clear that at low concentrations ( $<50 \mathrm{ppm}$ ) the quantity of metabolite produced increases disproportionately with exposure concentration (increasing slopes seen in fig 4). Run 2, for example, predicts Qmet-bm equal to $0.114 \mathrm{mg} /$ week at $0.005 \mathrm{ppm}$. At a concentration of $50 \mathrm{ppm}$ Qmet-bm is $1494 \mathrm{mg} /$ week. Above $50 \mathrm{ppm}$, the slope decreases slightly in most cases. Run 2 is an extreme case where the saturation effect at high dose is clear and the slope goes to zero above $150 \mathrm{ppm}$.

We attempted analytically to derive the functional relation between the rate of metabolite production by the bone marrow and the input concentration at steady state. Yet, due to the complexity of the system we were unable to obtain an explicit solution (even with the help of symbolic manipulation programs such as Mathematica and Maxima). A numerical solution was, however, obtained that verified the accuracy of the numbers computed by integration to within $0.33 \%$.

\section{Discussion}

Experimental studies usually involve high exposure concentrations relative to what is encountered in the environment. ${ }^{11-1320-27}$ This is necessary to detect benzene concentrations in the blood and exhaled air of the subjects when assay sensitivity is low. The quantities typically measured in human studies are the benzene concentrations in venous blood and expired air, and the concentration of phenol in urine. The four studies used in this investigation were selected from the body of human data because we judged their reports to be the most complete in terms of exposure procedure and reliable analytical methods..$^{911-13}$

Occupational studies are more realistic than experimental studies, but uncontrollable factors (for example, fluctuating and uncertain exposure concentration and differences in activity levels) make these data more uncertain. ${ }^{1-5}$ The measured quantities are usually the same as in an experimental study, but with fewer and unevenly spread data points over time. For these reasons, analysis of these data, and in particular modelling them for prediction purposes, is difficult and may give results with greater uncertainty and variability than modelling experimental studies. We therefore did not use data from occupational studies.

MODEL STRUCTURE AND PARAMETER DERIVATIONS

Two distinct sets of data led to two different parameter derivations of the model. Therefore the two groups of data: group 1 consisting of $\mathrm{T}$ and $\mathrm{Sr}$; and group 2 consisting of Sa74 and Sa75 seem to be incompatible. In terms of model parameters this translates into significantly different values for some of them. Table 3 shows that the univariate ranges obtained do not overlap for the blood to air partition coefficient. Also, it is likely that high dimensional correlation between parameters exists, distinguishing one PASS region from the other.

It is interesting that for both sets of parameters, the central compartment tissue to blood partition coefficient, $\mathrm{PCb}-\mathrm{cen}$, must fall in the range of 2.00 to 2.63 for both groups. This range covers only $7 \%$ of the sampled range. A true test of the model would be experimental verification of this result. Homogenised rabbit tissue to blood partition coefficients, for some of the tissues included in the central compartment, range from 1.08 to $1 \cdot 93,12$ a narrow range, but specific human values are unavailable.

The cause of the disparity between the two groups of model parameter sets is unclear. Some possibilities include: (a) the data simply represent two different underlying populations; (b) some measurements are poor or biased; (c) unreported differences in the experimental procedures exist; (d) the model structure is inadequate to describe the system dynamics; and (e) the limits for the criteria do not adequately account for the measurement uncertainty and between individual variability.

If the model structure is correct, then some conclusions about the data can be reached. Firstly, the differences in the blood to air partition coefficient could be indicative of pharmacogenetic differences in the subjects. Sato et al conducted their experiments in Japan, ${ }^{12} 13$ whereas the $\mathrm{T}$ and $\mathrm{Sr}$ experiments were performed in Czechoslovakia. ${ }^{911}$ Pharmacogenetic differences in the subjects could be responsible for the way in which benzene was absorbed, metabolised, or eliminated. Secondly, changes in the analytical measurement technology over the 20 year period, or the different techniques used by the researchers could also account for the disparate results. We have carefully reviewed the measurement and experimental procedures, however, and see no obvious differences that would account for the two parameter derivations.

There is always the possibility that the model structure is inadequate and validation of this model as a reliable predictor can only take place when additional data become available. For now, one can only postulate the meaning(s) of the results presented here. In previous work the toxicokinetic models were considered valid if they were able to visually 
fit the data. ${ }^{82-31}$ These models were used for risk assessment ${ }^{30}{ }^{31}$ although they were not validated with data pertaining to the quantity of interest. In this context the model presented here is of comparable quality.

The implication for risk assessment is that one should compare systematically the fits and model predictions obtained with different studies. This implies that the models should be formally fitted, with statistical techniques-for example, Monte Carlo simulations. Statistical fitting also gives confidence limits around model predictions, which should be a standard output of risk assessment.

\section{CRITERIA AND THEIR MEANING}

Confidence intervals, or more generally the distribution of predictions, represent several nested levels of variability: at least, analytical measurement errors, and within and between subject variability. It would be useful to have an estimate of population variability to judge whether results obtained in a Japanese study can be used for a Czechoslovakian population, for example. Yet, physiologically based models previously developed for the purpose of predicting doses to target tissues do not try to account for population variability. We propose that if the criteria for goodness of fit, as we define and use them here, account for measurement uncertainty and population variability, then both these effects are captured by the set of model parameters satisfying the criteria. As a consequence, each parameter derivation can be thought of as representing a possible member of the human population. The Monte Carlo method used here can therefore be presented as a "population toxicokinetic" approach.

The criteria were chosen to allow for population variability and uncertainty in the data. Sato et al reported SDs for their data. ${ }^{13}$ As this information was not available for all of the data, a standard within $50 \%$ was used. This is an underestimate of the variability in the urinary phenol data as Teisinger and FiserovaBergerova reported fivefold differences in values between subjects. ${ }^{9}$ For the end tidal air and blood benzene concentrations reported by Sato et $\mathrm{al}^{13} 50 \%$ more or less of the measured value is generally greater than two SDs of the mean for five subjects.

To assess the robustness of our findings, in particular the existence of two groups of data sets, with respect to the definition of the criteria, we attempted to fit the model across all data sets ( $T, \mathrm{Sr}, \mathrm{Sa74}$, and Sa75) while removing three points that were less than a factor of two above the reported analytical detection limits. No PASS point for these new criteria was found by Monte Carlo sampling (1 250000 simulations) and the clustering analysis again found two clusters.

\section{SIMULATION RESULTS}

Exposure rates are important to consider in regulatory policy because high exposure concentrations for short periods of time could result in different toxic effects than low expo- sures over long periods of time. Different rates of exposure were simulated to see if there was any difference in the predicted value for Qmet or area under the curve of benzene in bone marrow. As saturable reaction kinetics are known to describe the metabolism of benzene in the bone marrow and central compartments, it is possible that high concentrations for short periods of time could saturate the metabolic process, thereby producing dose rate effects.

For environmental exposures no dose rate effect was seen in the predictions of primary metabolites or for the benzene area under the curve in bone marrow. A slight but consistent dose rate effect appears at the level of occupational exposures (scenarios IV and V). The possibility of not having reached a steady state for exposure scenario IV was investigated by performing simulations up to five weeks. (As this scenario predicts the smaller values, not having reached steady state means that benzene is still accumulating in the bone marrow. The predicted values would only increase for exposure $V$ if it was not at a steady state after three weeks.) The predicted values between the fourth and fifth week were the same as those reported between the second and third weeks.

The model fitted to the Sa74-Sa75 data gives predictions of Qmet-bm with less variability than the model fitted to the T-Sr data. The distribution of these predictions seems close to $\log$-uniform. On the other hand, more variability was found in the prediction of area under the curve in bone marrow from the Sa74-Sa75 parameter sets. The predictions from both parameter sets seem to be uniformly distributed for areas under the curve for bone marrow. Although two distinct sets of model parameters were found, the predictions from both sets at low exposure concentration are similar (fig 2).

The predictions of Qmet made by both derivations from the model are different from the findings of Bois and Paxman for rats exposed to benzene. ${ }^{32}$ In rats, no dose rate effects were found at the primary metabolite level that we studied here. At the level of individual metabolites, however, important dose rate effects were found. Slight dose rate effects are already present in the disposition of primary metabolites in humans. These may not be biologically significant by themselves, but it can be suspected that individual active secondary metabolites are even more affected, with possibly a large impact on cancer risk. In this context, the application of a short-term exposure limit for benzene seems warranted, even if it is difficult to assess whether its current value ( $5 \mathrm{ppm}$ for 15 minutes) is over or under protective. More data on human metabolism of benzene is needed to precisely answer this question.

For continuous exposures, Qmet-bm predictions by Sa74-Sa75 parameter sets are generally greater than the predictions made by $\mathrm{T}$-Sr parameter sets. Of the $20 \mathrm{Sa} 74-\mathrm{Sa} 75$ predicted curves, nine of them showed generation of metabolites in excess of $1500 \mathrm{mg}$ a 
week within the exposure concentrations studied. Only one out of $20 \mathrm{~T}-\mathrm{Sr}$ curves showed production of metabolites in excess of $1500 \mathrm{mg}$ a week.

Variability is not only present between the two groups of parameter sets but also within each group. Thinking of each parameter set as a possible member of the population, we see that some subjects exhibit saturation of the production of metabolites in bone marrow, whereas others increase linearly or superlinearly. In the group represented by the Sa74-Sa75 parameter sets an exposure of 25 ppm produces a ninefold difference between the highest and lowest Qmet-bm. There is a 24-fold difference in the $\mathrm{T}-\mathrm{Sr}$ results at the same exposure concentration.

In recent risk assessments, it has been assumed that simple Michaelis-Menten kinetics describe correctly the relation between the applied dose and the mg equivalents of benzene metabolised per unit time. ${ }^{33} 34$ This study shows that Michaelis-Menten kinetics do not describe the relation at the site of action, the bone marrow. How, then, do we best extrapolate the high dose data to low doses in this context? The best approach should be the use of a general model, similar to ours, which can characterise the range of individual responses. A Michaelis-Menten approximation is easy to fit and would be appropriate for some individuals, but not for all. There is no guarantee that a simple Michaelis-Menten relation is even correct for extrapolating the population average. Assessment of cancer risk with average data should actually be avoided.

The findings described here: dose rate effects at occupational dose levels, $S$ shape form of the production of metabolites as a function of exposure concentrations, large between individual variability, by their potential importance for human risk assessment of benzene induced leukaemia, deserve further attention. The recent publication of a new set of data ${ }^{27}$ offers the potential for an independent verification of these results. Also, attempts are being made to acquire the missing information that made some of the older published reports unsuitable for this modelling investigation.

This work was supported by NIEHS grant number P42 ES04705-06 and by the Director, Office of Energy Research, Office of Health and Environmental Research, Human Health and Assessments Division of the United States Department of Energy under Contract No DE-AC03-76SF00098.

1 Sherwood RJ. Benzene: the interpretation of monitoring results. Ann Occup Hyg 1972;15:409-21.

2 Inoue $O$, Seiji K, Kasahara M, Nakatsuka H, Watanabe $T$ Yin S-G, et al. Quantitative relation of urinary pheno levels to breathzone benzene concentrations: a factory survey. Br f Ind Med 1986;43:692-7.

3 Drummond L, Luck R, Afacan AS, Wilson HK. Biological monitoring of workers exposed to benzene in the cok oven industry. Br F Ind Med 1988;45:256-61.

4 Perbellini L, Faccini GB, Pasini F, Cazzoli F, Pistoia S Rosellini $R$, et al. Environmental and occupational exposure to benzene by analysis of breath and blood. Br f Ind Med 1988;45:345-52.

5 Brugnone F, Perbellini L, Faccini GB, Pasini F, Danzi B, Maranelli G, et al. Benzene in the blood and breath of normal people and occupationally exposed workers. $A m \mathcal{F}$ Ind Med 1989;16:385-99.
6 Wallace LA, Pellizzari ED, Hartwell TD, Davis V, Michael LC, Whitmore RW. The influence of personal activities on exposure to volatile organic compounds. Environ Res 1989;50:37-55.

7 McDermott HJ, Vos GA. Service station attendants' exposure to benzene and gasoline vapors. Am Ind Hyg Assoc $\mathrm{f}$ 1979;40:315-21.

8 Travis CC, Quillen JL, Arms AD. Pharmacokinetics of benzene. Toxicol Appl Pharmacol 1990;102:400-20.

9 Teisinger J, Fiserova-Bergerova V. Valeur comparée de la détermination des sulfates et du phénol contenus dans l'urine pour l'évaluation de la concentration du benzène dans l'air. Archives des Maladies Professionnelles et de Medicine du travail 1955;16:221-32.

10 Docter HJ, Zielhuis RL. Phenol excretion as a measure of benzene exposure. Ann Occup Hyg 1967;10:317-26.

11 Srbova J, Teisinger J, Skramovsky S. Absorption and elimination of inhaled benzene in man. Archives of Industrial Hygene and Occupational Medicine 1950;2:1-8.

12 Sato A, Nakajima T, Fujiwara $Y$, Hirosawa $K$ Pharmacokinetics of benzene and toluene. Int Arch Arbeitsmed 1974;33:169-82.

13 Sato A, Nakajima T, Fujiwara Y, Murayama N. Kinetic studies on sex difference in susceptibility to chronic benstudies on sex difference in susceptibility to chronic ben-
zene intoxication-with special reference to body fat zene intoxication-with special refer
content. Br f Ind Med 1975;32:321-8.

14 Woodruff TJ, Bois FY, Auslander D, Spear RC. Structure and parameterization of pharmacokinetic models: their impact on model predictions. Risk Anal 1992;12: 189-201.

15 Bois FY, Woodruff TJ, Spear RC. Comparison of three physiologically based pharmacokinetic models of benzene disposition. Toxicol Appl Pharmacol 1991;110: 79-88.

16 Spear RC, Bois FY, Woodruff T, Auslander D, Parker J, Selvin S. Modeling benzene pharmacokinetics across three sets of animal data: parametric sensitivity and risk three sets of animal data: parametric sen
implications. Risk Anal 1991;11:641-54.

$17 \mathrm{Li} \mathrm{H}$, Watanabe K, Auslander D, Spear RC. Model parameter estimation: understanding parametric structure. Ann Biomed Eng 1994(submitted)

8 Brunnemann KD, Kagan MR, Cox JE, Hoffmann D. Determination of benzene, toluene and 1,3-butadiene in cigarette smoke by GC-MSD. Experimental Pathology 1989;37:108-13.

19 Byrd GD, Fowler KW, Hicks RD, Lovette ME, Borgerding MF. Isotope dilution gas chromatographymass spectrometry in the determination of benzene, toluene, styrene and acrylonitrile in mainstream cigarette smoke. F Chromatogr Sci 1990;503:359-68.

20 Hunter CG, Blair D. Benzene: pharmacokinetic studies in man. Ann Occup Hyg 1972;15:193-9.

21 Nomiyama K, Nomiyama $H$. Respiratory retention, uptake and excretion of organic solvents in man. Int Arch Arbeitsmed 1974;32:75-83.

22 Nomiyama K, Nomiyama H. Respiratory elimination of organic solvents in man. Int Arch Arbeitsmed 1974;32: 85-91.

23 Sherwood RJ. Comparative methods of biologic monitoring of benzene exposures. In: Proceedings of The Annual Conference on Environmental Toxicology. Fairborn, Ohio: National Technical Information Service, 1972:29-52.

24 Sherwood RJ. Pharmacokinetics of benzene in a human after exposure at about the permissible limit. Ann NY Acad Sci 1988;534:634-47.

25 Berlin M, Holm S, Knutsson P, Tunek A. Biological threshold limits for benzene based on pharmacokinetics of inhaled benzene in man. Arch Toxicol 1979;suppl 2: 305-310.

26 Berlin M, Gage J, Gullberg B, Holm S, Knutsson P, Tunek A. Breath concentration as an index of the health risk from benzene. Scand $f$ Work Environ Health 1980;6:104-11.

27 Pekari K, Vainiotalo S, Heikkilä P, Palotie A, Luotamo M, Riihimäki V. Biological monitoring of occupational exposure to low levels of benzene. Scand $\mathcal{f}$ Work Environ Health 1992;18:317-22.

28 Ramsey JC, Andersen M. A physiologically based description of the inhalation pharmacokinetics of stryene in rats tion of the inhalation pharmacokinetics of stryene in ra
and humans. Toxicol Appl Pharmacol 1984;73:159-75.

29 Paustenbach DJ, Clewell III HJ, Gargas ML, Andersen ME. A physiologically based pharmacokinetic model for inhaled carbon tetrachloride. Toxicol Appl Pharmacol 1988;96:191-211.

30 Reitz RH, McCroskey PS, Park CN, Andersen ME, Gargas ML. Development of a physiologically based pharmacokinetic model for risk assessment with 1,4 dioxane. Toxicol Appl Pharmacol 1990;105:37-54

31 Leung H, Paustenbach DJ. Cancer risk assessment for dioxane based upon a physiologically-based pharmacokinetic approach. Toxicol Lett 1990;51:147-62.

32 Bois FY, Paxman DG. An analysis of exposure rate effects for benzene using a physiologically based pharmacokinetic model. Regul Toxicol Pharmacol 1992;15:122-36.

33 Bailer AJ, Hoel DG. Metabolite-based internal doses used in a risk assessment of benzene. Environ Health Perspect in a risk assessm.

34 Beliles RP, Totman LC. Pharmacokinetically based risk assessment of workplace exposure to benzene. Regul Toxicol Pharmacol 1989;9:186-95. 